\title{
Postnatal home visits by health extension workers in rural areas of Ethiopia: a cross- sectional study design
}

Yemane Berhane Tesfau ${ }^{1,2^{*}}$ (D), Alemayehu Bayray Kahsay ${ }^{2}$, Tesfay Gebregzabher Gebrehiwot ${ }^{2}$, Araya Abrha Medhanyie ${ }^{2}$ and Hagos Godefay ${ }^{3}$

\begin{abstract}
Background: In low-income countries like Ethiopia, where families have poor access to or do not utilize the services of formal health care systems, community health workers provide postnatal care services through home visits. However, the extent and effectiveness of home-based postnatal visits by community health workers such as the Ethiopian health extension workers (HEWs) are not well explored. This community -based study aimed to determine the coverage, contents of postnatal home visits and associated factors by health extension workers in Northern Ethiopia.
\end{abstract}

Methods: We conducted a community based cross-sectional study in the rural Districts in Northern Ethiopia from August to September 2018. A total of 705 mothers who gave a live birth in the year preceding the survey were selected using multistage random sampling. A structured questionnaire was applied to collect data by interviewing the mothers. Data were analyzed using SPSS version 22 statistical software. Association of postnatal home visits with possible explanatory variables was investigated using logistic regression.

Results: One hundred and two (14.5\%) mothers and newborns received PNC home visit within three days after birth from HEW and 170(24.1\%) reported postnatal home visits within 42 days. Among the mothers who received postnatal home visits, 6.5\% measured their blood pressure, 11.2\% measured their temperature, 20\% counseled about family planning, $16.5 \%$ counseled on newborn danger signs, $11.2 \%$ counseled on the skin to skincare of the newborn and $14.1 \%$ of their newborns were measured their weight at home. Mothers who received at least one home visit during pregnancy (AOR, 7.49; Cl 3.55-15.80), participated in pregnant women forum (AOR, 3.16; $\mathrm{Cl} 1.67-$ 5.99), notified their birth (AOR, 6.16; Cl 3.50-10.84) and those members of community health insurance (AOR, 1.87; Cl 1.13-3.10) were factors associated with postnatal home visit by a health extension worker.

Conclusion: The coverage of postnatal home visits by health extension workers remains low in rural districts of Northern Ethiopia. The existing health systems should consider interventions that improve pregnancy and birth notification strategies and more efforts should be made at improving community-based participation and linkages with community health workers.

Keywords: Postnatal home visits, Health extension workers, Rural districts, Northern Ethiopia

\footnotetext{
* Correspondence: yemaneberhane12@gmail.com

${ }^{1}$ College of Medicine and Health Sciences, Adigrat University, Adigrat, Ethiopia

${ }^{2}$ Mekelle University, College of Health Sciences, School of Public Health, Mekelle, Ethiopia

Full list of author information is available at the end of the article
}

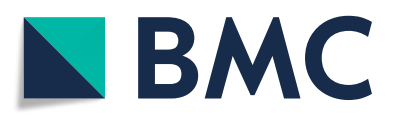

(- The Author(s). 2020 Open Access This article is licensed under a Creative Commons Attribution 4.0 International License, which permits use, sharing, adaptation, distribution and reproduction in any medium or format, as long as you give appropriate credit to the original author(s) and the source, provide a link to the Creative Commons licence, and indicate if changes were made. The images or other third party material in this article are included in the article's Creative Commons licence, unless indicated otherwise in a credit line to the material. If material is not included in the article's Creative Commons licence and your intended use is not permitted by statutory regulation or exceeds the permitted use, you will need to obtain permission directly from the copyright holder. To view a copy of this licence, visit http://creativecommons.org/licenses/by/4.0/. The Creative Commons Public Domain Dedication waiver (http://creativecommons.org/publicdomain/zero/1.0/) applies to the data made available in this article, unless otherwise stated in a credit line to the data. 


\section{Background}

Despite the remarkable achievements observed, about 4 million neonates and 287,000 maternal deaths occur each year, mostly in low- income countries, due to maternal and newborn complications occurring within $24 \mathrm{~h}$ of birth and thereafter [1]. In Ethiopia, maternal and neonatal mortality remains the highest among the world, at 412/100,000 and 30/1000, respectively. The trends from the previous surveys in Ethiopia showed that a continuous decline in infant and under -5 mortality preceding each respective survey, however, the trend among the neonatal mortality decreased from 39 to 29 between the 2005 and 2016 EDHS, but has remained stable since the 2016 EDHS [2].

Despite the fact improvements observed with antenatal care (ANC) and facility delivery, postnatal care (PNC) utilization coverage remains low due to many reasons such as unavailability, inaccessibility, poor quality of health services, socio-cultural beliefs, awareness on danger signs of postnatal period, and distance [3-10]. Even with different multiple interventions, postnatal maternal and newborn care utilization health facility remains low $[2,11]$. Studies also showed that a significant proportion of mothers prefer to return home or discharged within a few hours after delivery, which makes them not receive the required care $[12,13]$.

Studies in low and middle -income countries with high new-born mortality demonstrated that early postnatal home visits, by community health workers help to reduce neonatal deaths and improve maternal and neonatal health. For example, studies conducted in India, Bangladesh, and Pakistan have shown that home visits can reduce deaths of newborns by $30-61 \%$ in developing countries where there is a high mortality. In particular, home visits improved coverage of the key high-impact and cost-effective neonatal interventions such as early initiation of breastfeeding, skin-to-skin contact between newborns and their mothers, delayed bathing of the newborn, hygienic care of the baby's umbilical cord stump [14].

Based on the experiences and evidence from South Asian trials, in 2009, World Health Organization (WHO) and United Nations Children's Fund (UNICEF) issued a joint statement recommending postnatal home visits (PNHVs) for delivery of postnatal care. Following the 2009 Joint Statement, many countries adopted policies to deliver postnatal home visits. Among the 75 countries included in the Countdown to 2015 report, 59 have policies deliver such home visits within 1 week of birth $[15,16]$.

The health extension program, which was launched in 2003 contributed to mobilizing community members towards the utilization of antenatal care and institutional delivery. HEWs were trained to give basic maternal and child health care and improve the health of the mothers and newborns during the antenatal, delivery and postnatal period and HEWs are expected to spend $75 \%$ of their time in the community and provide essential health services through the house to house visit [17].

Routine home visiting by community health workers during the postnatal period considers identification, assessment, management, and referral of both mother and baby for care. Postnatal care services provided at home for the mother include assessing general condition, checking vital signs and danger signs. For the newborns, it includes a general body examination, checking general danger signs, checking the cord for any bleeding and infection, and assessing breast feeding [18].

Studies on the coverage of the postnatal visit within $48 \mathrm{~h}$ showed low [19] and the coverage within 3 days after delivery from three Countries (Bangladesh, Nepal, and Malawi) by Community Health Workers (CHWs) showed that 57,50 , and $11 \%$ respectively, and the pooled results of the study in these countries found that early visits were more likely if a mother had been visited by CHWs during pregnancy, birth notification by $\mathrm{CHWs}$, and home deliveries [20].

In Ethiopia, since the implementation of the health extension program (HEP), few studies have published findings on the coverage of PNHVs by HEWs. In Southern Ethiopia, $12.4 \%$ of mothers and their neonates were visited by the HEWs during the first month of birth and the major factors associated with early PNHVs were HEWs visit home during pregnancy, skilled delivery, and having HEW's cell phone and no association were observed with maternal socio-demographic characteristics and early PNHVs [21].

In the northern Ethiopia, to improve the lives of mothers and newborns, different activities have conducted by HEWs in line with the government's policies and strategies and EDHS report showed the percentage of facility-based postnatal care utilization within the first 2 days after delivery was $45.4 \%$ [22]. However, paucity exists on the evidence about the coverage of early PNHVs by HEWs. Moreover, little is known about the contents of the care given during PNHVs. Therefore, the study aimed to determine the coverage and contents of PNHVs and associated factors by HEWs, in rural Tigray, northern Ethiopia.

\section{Methods \\ Study setting}

The study was conducted in four districts of the South Eastern Zone of Tigray region, namely, Dogua Tembien, Enderta, Hintalo-Wajerat, and Seharti-Samre. This zone surrounds the capital city of Tigray region, Mekelle. The four districts had a total population of 567,735 with the total households estimated at 129,031. The zone has a 
total of 88 villages/kebeles (17-Enderta, 24- DoguaTembien, 23- Seharti-Samre and 24- Hintalo-Wajerat district). The estimated live births with children aged 11 months and below in the study area were 17,600. In 2018, there were 03 primary hospitals, 24 health centers and 75 health posts in the study zone. Concerning the number of health professionals, there were 731 health care providers in the zone out of which 183 were health extension workers (HEWs) [23].

\section{Study design and population}

We conducted a community-based cross-sectional survey among mothers who gave live birth in the past year before the survey/data collection.

\section{Sample size and sampling technique}

A single population proportion formula was used to determine the sample size. To consider the design effect of 1.7, we assumed a rate of homogeneity (Roh $=0.05)$ and Coefficient of variance $(\mathrm{CV}=0.25)$ for unequal size clusters. Using a $10 \%$ of none response rate the total sample size was 705 . The study employed a multi-stage sampling at the kebele and household level. All districts in the zone were involved in the study. In the first stage, 30 clusters/ kebeles were selected using simple random sampling out of 88 clusters found in the zone (6-Enderta woreda, 8Dogua-Tembien, 8- Seharti-Samre and 8- HintaloWajerat). The list of mothers with infants less than 1 year was registered in each cluster. A total of 138 participants from Enderta, 178 participants from Dogua Tembien, 195 participants from Seharti-Samre and 194 participants from Hintalo-Wajerat district were recruited.

\section{Data source and measurement}

Data were collected with an interviewer-administered structured questionnaire that was adapted from Ethiopia demography health survey (EDHS) and the last $10 \mathrm{~km}$ (L10K) survey [22, 24]. The tool contains items regarding socio-demographic, status towards model household, community based participations like pregnant women forum, women development group (WDG), and community health insurance membership, availability of HEW's cell phone at home, time taken to visit the household, ANC attendance (both facility and home), place of delivery, birth notification, attendants at birth, postnatal visits and contents of PNC provided. It was initially prepared in English and then translated into the local language (Tigrigna) and translated back to English by different language experts. The questionnaire was pre-tested prior to the commencement of actual data collection outside the study districts. A total of 20 field workers (BSc and above in nursing, and midwifery) were recruited for the data collection and 2 days training was given for the data collectors. The interviewers visited each eligible woman at her home to administer the survey. Day to day supervision of the data collection was made by the principal investigator and supervisors of the study. A protocol that guides the design, implementation and management of the survey was developed and given to the data collectors. The supervisors reviewed all completed questionnaires in the field for accuracy, consistency, and completeness. Data were collected from August - September 2018. In this study, the postnatal home visit is defined at least one home visit by HEW within 3 days after childbirth. The coverage of postnatal home visits was defined as the percentage of women and/or newborns that were visited at home within 3 days after delivery. The contents of the postnatal home visits were measured by mothers/caretakers words.i.e.by mention or not mention technique $($ mention $=1$, not mention $=0$ ).

\section{Data analysis}

The data were coded, entered, edited, and analyzed using SPSS Version 22.0. Descriptive statistics like: proportion, mean, and standard deviation were used and the results

Table 1 Sociodemographic characteristics of mothers and their neonates in the rural Tigray region, Northern Ethiopia, 2018

\begin{tabular}{|c|c|c|}
\hline Variables & Frequency & Percentage \\
\hline \multicolumn{3}{|l|}{ Current maternal age } \\
\hline $18-24$ & 245 & 34.8 \\
\hline $25-29$ & 183 & 26.0 \\
\hline $30-39$ & 250 & 35.4 \\
\hline $40-49$ & 27 & 3.8 \\
\hline \multicolumn{3}{|l|}{ Maternal education } \\
\hline No education & 284 & 40.3 \\
\hline Primary education & 250 & 35.5 \\
\hline Secondary education and above & 171 & 24.2 \\
\hline \multicolumn{3}{|l|}{ Marital status } \\
\hline Married and/ live together & 647 & 91.8 \\
\hline Divorced/separated/widowed & 58 & 8.2 \\
\hline \multicolumn{3}{|l|}{ Sex of newborn } \\
\hline Male & 357 & 50.6 \\
\hline Female & 348 & 49.4 \\
\hline \multicolumn{3}{|l|}{ Children ever born } \\
\hline 1 & 163 & 23.1 \\
\hline 2 & 167 & 23.7 \\
\hline 3 & 113 & 16 \\
\hline+4 & 262 & 37.2 \\
\hline \multicolumn{3}{|c|}{ Distance to nearest health facility (one way) } \\
\hline$<30 \min$ & 501 & 71.1 \\
\hline $30 \mathrm{~min}$ to $<1 \mathrm{~h}$. & 160 & 22.7 \\
\hline$>=1 \mathrm{~h}$ & 44 & 6.2 \\
\hline
\end{tabular}




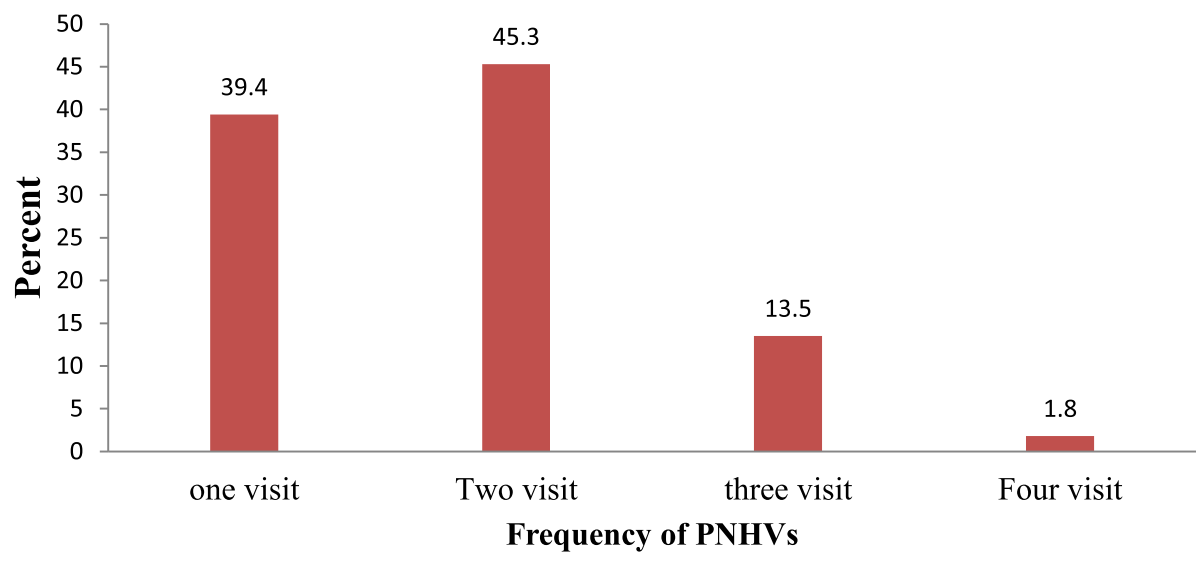

Fig. 1 Proportion of mothers who gave birth by the number of visit received in Rural Tigray, northern Ethiopia

were presented using text, tables, and figures. Binary logistic regression was used to check the associations between explanatory variables and postnatal home visit. Multi co-linearity was checked by using Variance inflation factor and model fitness using Hosmer and Lemeshow Test was conducted prior to running to multivariable analysis. A $p$-value of less than 0.05 was considered to be statistically significant.

\section{Ethics approval and consent to participate}

Ethical approval was obtained from the Institutional Review Board of Mekelle University (No.1437/2018). Verbal consent was also obtained from the study participants. We secured verbal consent as a significant number of the study subjects were unable to read and write. The use of verbal consent was approved by the ethics committee.

\section{Result}

\section{Participant characteristics}

We enrolled a total of 705 mothers with a $100 \%$ response rate in the study; of these, about $250(35.5 \%)$ were in the age group of 30 to 39 years with the mean age of 27.5 years $( \pm 5.77)$. About three-fourth, 502(71.2\%) of the study participants can read and write a simple sentence, though, 284(40.3\%) mothers had never attended a school. Almost all 701(99.4\%) participants were Christian Orthodox. More than half 418(59.3\%) of mothers were visited during pregnancy by a HEW. However, $371(88.8 \%)$ of the mothers did not receive visit during their first trimester. About 684(97\%) of respondents reported making at least one antenatal care visit to a health facility, and $247(36.1 \%)$ reported 4 or more visits. Above half of the respondents, 390(57\%) initiated antenatal care before 16 weeks of pregnancy. Facility deliveries were reported by $629(89.2 \%)$ of the participants, however, $591(81.8 \%)$ of them had a facility stay of less than $24 \mathrm{~h}$ post-delivery. The average number of live births per mother was $3.12( \pm 1.9)$. Concerning to the distance from the health post majority of the mothers, 501(71.1\%) found less than $30 \mathrm{~min}$ of walking distance (Table 1).

\section{Postnatal home visit coverage}

Overall, $102(14.5 \%)$ with (95\% CI $=12.0$ to 17.3$)$ of mothers and their newborns received a home visit from a HEW within 3 days after birth. Within the Postnatal period, about 273 PNHVs and 170(24.1\%) participants

Table 2 Coverage of PNHVs by HEWs in rural Tigray Northern Ethiopia, 2018

\begin{tabular}{|c|c|c|}
\hline $\begin{array}{l}\text { Maternal and newborn postnatal home receipt } \\
\text { coverage }(N=705)\end{array}$ & Frequency & $\%$ \\
\hline \multicolumn{3}{|l|}{ Overall PNHVs within 42 days after delivery } \\
\hline No & 525 & 75.9 \\
\hline Yes & 170 & 24.1 \\
\hline \multicolumn{3}{|c|}{ PNHV receipt within three days after delivery $(n=705)$} \\
\hline No & 603 & 85.5 \\
\hline Yes & 102 & 14.5 \\
\hline \multicolumn{3}{|l|}{ Initial PNHVs $(n=170)$} \\
\hline Within $24 \mathrm{~h}$ & 39 & 22.9 \\
\hline 2-3 days & 63 & 37.1 \\
\hline 4-7 days & 53 & 31.2 \\
\hline After 7 days & 15 & 8.8 \\
\hline \multicolumn{3}{|l|}{ Second PNHVs $(n=77)$} \\
\hline $2-3$ days & 06 & 7.8 \\
\hline 4-7 days & 36 & 46.8 \\
\hline After 7 days & 35 & 45.4 \\
\hline \multicolumn{3}{|l|}{ Third PNHVs $(n=23)$} \\
\hline 4-7 days & 05 & 21.7 \\
\hline After 7 days & 18 & 78.3 \\
\hline \multicolumn{3}{|l|}{ Fourth PNHVs $(n=3)$} \\
\hline After 7 days & 03 & 100 \\
\hline
\end{tabular}


PNHVs by place of delivery

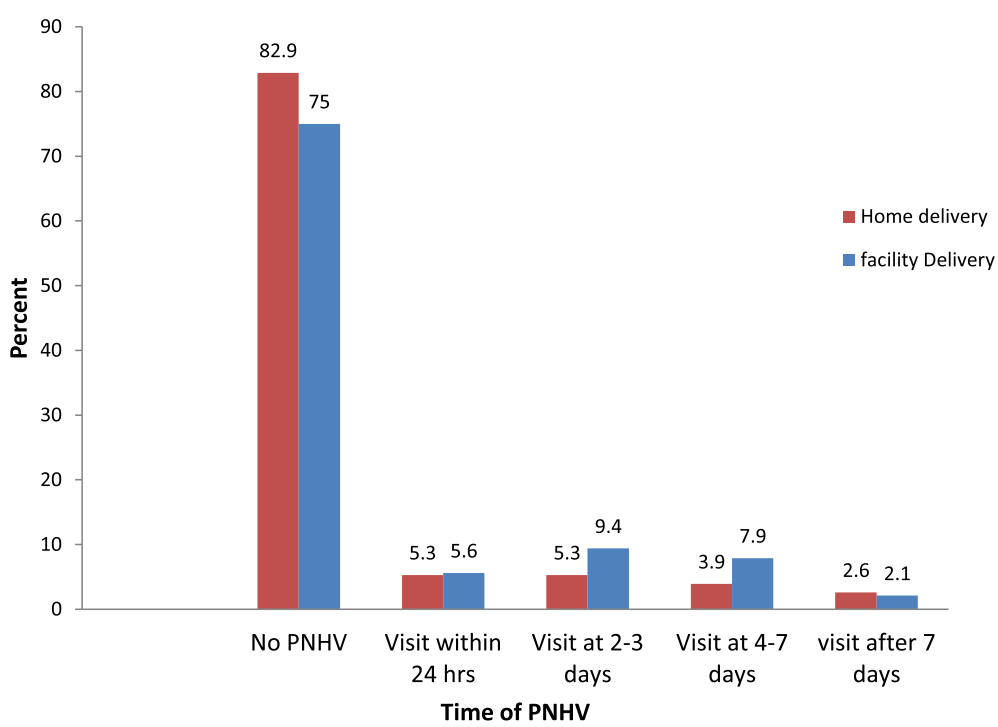

Fig. 2 Percentage of mothers who received PNHVs within 42 days after birth by place of delivery

were visited by the HEWs. Out of the PNHVs performed, 67(39.4\%) of mothers and their neonate received only one visit, 77(45.3\%) received two visits, $23(13.5 \%)$ visited three times, and 03(1.8\%) received four times by the HEWs (Fig. 1). Out of the total of home deliveries, only $08(10.5 \%)$ of mothers and their newborns received PNHVs within 3 days after delivery. Table 2 shows the timing of each visit where only $39(22.9 \%)$ mothers and their newborns received PNHV within the critical time i.e. within $24 \mathrm{~h}$. In the second visit, the majority of the participants $71(92.2 \%)$ received PNHVs after the third day of delivery. In the third visit $18(78.3 \%)$ of mothers and their neonates received PNHVs after 7 days. Six out of 77 participants $(7.8 \%)$ of their second visit were at 23 days and $5 / 23(21.7 \%)$ of the visit were at $4-7$ days (Table 2).

Out of 76 home deliveries, only 13(17.1\%) and 08(10.5\%) of mothers and their newborn received PNHVs in the postnatal period and within 3 days after delivery respectively. Whereas, $472(75 \%)$ of facility deliveries did not receive PNHVs after delivery. Immediately after delivery, $55(7.8 \%)$ and $31(4.4 \%)$ of mothers were visited by women development group (WDG) leaders and Traditional birth attendants respectively (Fig. 2).

Out of the total facility deliveries, 114 (18.2\%) received initial postnatal care at the facility within $24 \mathrm{~h}$. Because

\section{Percent of mothers and/newborns received PNHV from HEWs based on the schedule}

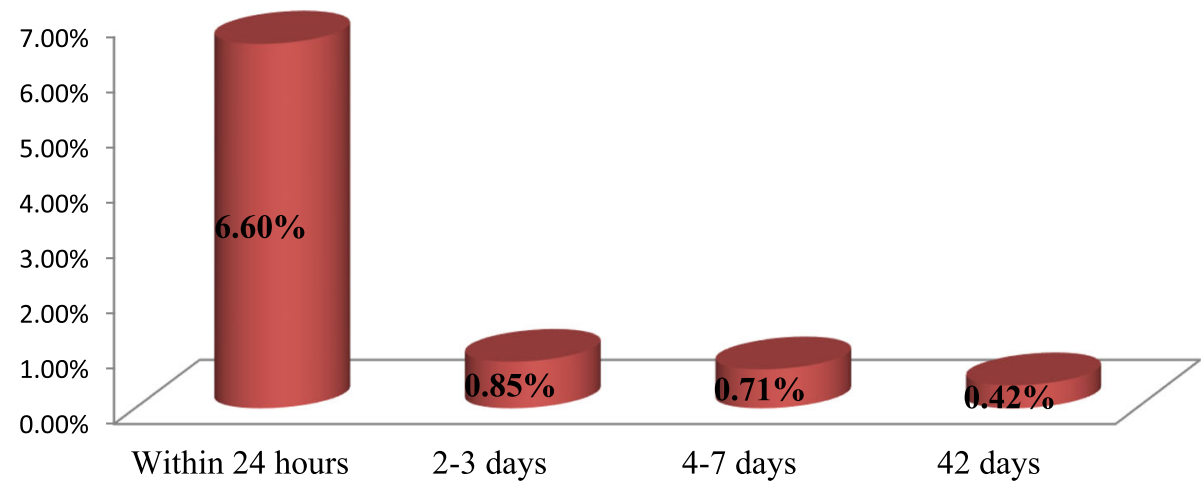

Fig. 3 Percentage of mothers and newborns who received PNHVs from HEWs based on the schedule 
Table 3 Contents of maternal PNC provided by HEWs in rural Tigray, Northern Ethiopia, 2018

\begin{tabular}{ll}
\hline Postnatal contents & Frequency (N/\%) \\
\hline The proportion of mothers: & \\
Underwent body examination & $37(21.8 \%)$ \\
Checked heavy bleeding & $67(39.4 \%)$ \\
Measured their body Temperature & $19(11.2 \%)$ \\
Measured their Blood pressure & $11(6.5 \%)$ \\
Counseled about personal hygiene & $48(28.2 \%)$ \\
Counseled about family planning & $34(20 \%)$ \\
Checked about TT immunization & $6(3.5 \%)$ \\
Counseled about breastfeeding & $54(31.8 \%)$ \\
Counseled about own feeding & $57(33.5 \%)$ \\
Checked for Iron intake & $4(2.4 \%)$ \\
\hline
\end{tabular}

of this initial PNHV at home within $24 \mathrm{~h}$ was calculated out of 591 delivered mothers and it was 39 (6.6\%). Six (0.85\%) out of 705 mothers received PNHV their second visit in 2-3 days; 5/0.71\%) mothers and their newborns received their third visit in 4-7 days and only 03/0.42\%) mothers received their fourth visit at 42 days (Fig. 3).

\section{Postnatal care contents provided during a home visit}

Out of 170 mothers who were visited at home, $67(39.4 \%)$ of them were checked for heavy bleeding, $75(44 \%)$ of mothers were advised about their own postnatal danger sign, $19(11.2 \%)$ of mothers were measured their temperature, $11(6.5 \%)$ of mothers were measured their blood pressure at home and no mother was mentioned counseling about safe sexual practice (Table 3).

(Fig. 4) Showed newborn contents mentioned by the mothers. A general assessment of newborns was done for 44(25.9\%), newborn weighed 24(14.1\%), checked their cord 70(41.2\%), and 26(15.3\%) newborns were measured their temperature.

\section{Factors associated with PNHV receipt}

We calculated the adjusted odds ratio of maternal characteristics associated with the PNHV receipt. The results revealed that, mothers who received at least one home visit during pregnancy by HEWs (AOR, 7.49; CI 3.55-15.80), participated in pregnant women forum (AOR, 3.16; CI 1.67-5.99), notified their birth (AOR, 6.16; CI 3.50-10.84) and those members of community health insurance (AOR, 1.87; CI 1.133.10) had statistically significant positive association with postnatal home visits by health extension workers within 3 days after delivery. Educational status, the status of mothers on model family, time taken to travel health post, and availability of HEW's cell phone at home did not show any statistically significant association with postnatal home visits (Table 4).

\section{Discussion}

This study addresses an important but relatively neglected area of maternal and newborn care in northern Ethiopia. Almost all studies in northern Ethiopia have focused on facility postnatal care utilization and associated factors; PNHVs by HEWs were not assessed.

Our study showed a low coverage, 102(14.5\%) mothers and newborns received PNHVs within 3 days after delivery. In our study, throughout the postnatal period, 170 (24.1\%) mothers and their newborns received PNHVs by the HEWs. Full contents of PNHV both for the mother and newborn were not addressed by the HEWs. Home visits during pregnancy by HEWs, participated in pregnant women forum, birth notification to HEWs and being members of community health insurance had a

\section{Newborn Postnatal contents}

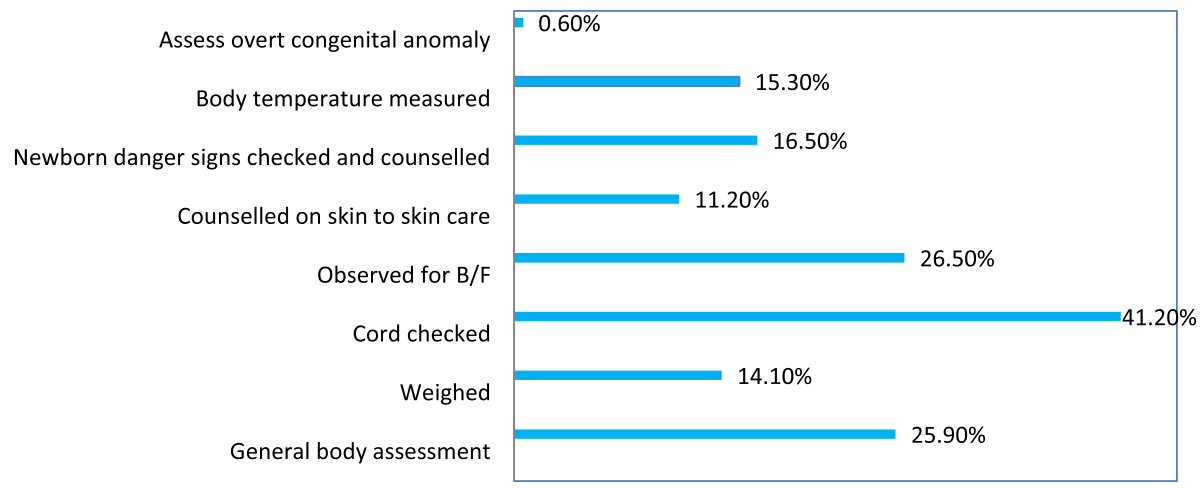

Fig. 4 Type of PNHV contents delivered to newborns, in rural Tigray, Northern Ethiopia 
Table 4 Association of participants' characteristics with postnatal home visit receipt, rural Tigray, northern Ethiopia, 2018 ( $N=705$ )

\begin{tabular}{|c|c|c|c|c|c|c|}
\hline \multirow[t]{2}{*}{ Characteristics of respondents } & \multicolumn{2}{|c|}{ Received PNHVs } & \multicolumn{2}{|c|}{ Crude Odds Ratio } & \multicolumn{2}{|c|}{ Adjusted Odds Ratio } \\
\hline & Yes (\%) & No (\%) & Odds ratio & $95 \% \mathrm{Cl}$ & Odds ratio & $95 \% \mathrm{Cl}$ \\
\hline \multicolumn{7}{|l|}{ Educational status of the mother } \\
\hline No education & $34(12.0)$ & $250(88.0)$ & 1.00 & & 1.00 & \\
\hline Primary Education & $31(12.4)$ & $219(87.6)$ & 1.04 & $0.62-1.75$ & 0.86 & $0.48-1.57$ \\
\hline Secondary education. and above & 37 (21.6) & $134(78.4)$ & 2.03 & $1.22-3.38$ & 1.56 & $0.85-2.87$ \\
\hline \multicolumn{7}{|l|}{ Model household status } \\
\hline Did not hear and/not model family & $59(12.7)$ & $407(87.3)$ & 1.00 & & 1.00 & \\
\hline Yes/certified or non-certified model family & $20(29.0)$ & $49(71.0)$ & 2.82 & $1.56-5.07$ & 1.24 & $0.61-2.52$ \\
\hline Working towards model family & $23(13.5)$ & $147(86.5)$ & 1.08 & $0.64-1.81$ & 0.73 & $0.40-1.33$ \\
\hline \multicolumn{7}{|l|}{ ANC visit by HEW (at least1) } \\
\hline No & $9(3.1)$ & $278(96.9)$ & 1.00 & & 1.00 & \\
\hline Yes & $93(22.2)$ & $325(77.8)$ & 8.84 & $4.38-17.85$ & $7.49^{*}$ & $3.55-15.80$ \\
\hline \multicolumn{7}{|l|}{ HEWs cell phone available } \\
\hline No & $34(8.9)$ & $346(91.1)$ & 1.00 & & 1.00 & \\
\hline Yes & $68(20.9)$ & $257(79.10$ & 2.69 & $1.73-4.19$ & 1.31 & $0.78-2.21$ \\
\hline \multicolumn{7}{|l|}{ Participation in Pregnant women forum } \\
\hline No & $15(4.7)$ & $306(95.3)$ & 1.00 & & 1.00 & \\
\hline Yes & $87(22.7)$ & $297(77.3)$ & 5.98 & $3.38-10.58$ & $3.16^{*}$ & $1.67-5.99$ \\
\hline \multicolumn{7}{|l|}{ Community health insurance membership } \\
\hline No & $51(10.7)$ & $425(89.3)$ & 1.00 & & 1.00 & \\
\hline Yes & $51(22.3)$ & $178(77.7)$ & 2.39 & $1.56-3.66$ & $1.87^{*}$ & $1.13-3.10$ \\
\hline \multicolumn{7}{|l|}{ Birth notification } \\
\hline No & $19(4.7)$ & $387(95.3)$ & 1.00 & & 1.00 & \\
\hline Yes & $83(27.8)$ & $216(72.2)$ & 7.83 & $4.63-13.24$ & $6.16^{*}$ & $3.50-10.84$ \\
\hline \multicolumn{7}{|l|}{ Time taken to Health post } \\
\hline$<30 \min$ & $81(16.2)$ & $420(83.8)$ & 1.00 & & & \\
\hline $30-1 \mathrm{~h}$ & $16(10)$ & $144(90)$ & 0.58 & $0.33-1.02$ & 0.73 & $0.38-1.39$ \\
\hline$>1 \mathrm{~h}$ & $5(11.4)$ & 39 (88.6) & 0.66 & $0.25-1.74$ & 0.92 & $0.30-2.81$ \\
\hline
\end{tabular}

statistically significant association with receipt of postnatal home visits.

Evidences showed that early postnatal home visits by community health workers reduce maternal and newborn morbidity and mortality, especially at higher coverage [14]. However, our finding showed that the percentage of mothers and neonates who received PNHV within 3 days was 102(14.5\%). This is consistent with the studies on the contact coverage of postnatal visits within $48 \mathrm{~h}$ of birth following home births in Africa and Asia [19, 25]. Previous studies also demonstrated that the coverage of PNHVs was low with only 4 countries having over 50\% [26]. Our finding is higher than a study conducted on newborn care practices at home and in health facilities in Ethiopia and Malawi [27, 28]. However, it is very low compared to other studies done in Uganda, Nepal, Bangladesh, and Ghana [20, 29, 30]. This might be due to HEWs were engaged in different activities and loaded because of increased population and multiple other competing responsibilities $[31,32]$.

It is known that timely and quality delivery of maternal and newborn interventions at high coverage can reduce maternal and newborn complications. However, the contents of postnatal care provided by HEWs during PNHVs to the mother and newborn, in general, were low in this study compared to previous studies [29]. This could be due to little attention given towards postnatal services by HEWs, and government officials; as evidenced from our finding that showed 418(59.3\%) mothers received at least one ANC visit at home.

The findings regarding the association of home visits during pregnancy and PNHVs were mixed [33]. In this study, HEWs household visits during pregnancy had a significant positive association with receipt of PNHVs by the mothers and their newborns. ANC offers women the 
opportunity to access health information and to appreciate the importance of PNC. Similar findings were reported from different studies [34-36]. This might be due to frequent contact during pregnancy and forming close relationships with the mothers so that they can notify them at the delivery or in the postnatal period. Other reasons might be the HEWs were aware of the expected date of delivery (EDD) and could contact through community linkages. Thus, rigorous efforts by HEWs are necessary to visit pregnant women at home.

Early visits were also more likely if a mother had notified the HEW about the birth. Similar findings were noticed when CHWs are notified of the birth early, they are much more likely to visit home after delivery. Previous studies also have shown that mothers who have notification of their birth increase the maternal and newborn health service utilization [34].

Consistent with previous studies, Participation in the pregnant women forum was associated with receipt of postnatal home visits by HEWs. Thus, it is an opportunity to receive a continuum of care from pre-facility, facility and post facility [34].

Mothers that were members of community health insurance were more likely to receive PNHVs.

Even though, a paucity of information on the association of this variable with PNHVs found, evidences showed that maternal postnatal visit is more likely if the mother is a member of community health insurance [8]. This might also although, a postnatal home visit is for free, the need for health-seeking of the community and communication and linkage with service providers increased. Another possible reason could be mothers who received postnatal home visits might be with birthrelated complications.

Therefore, in addition to pregnancy visits, efforts should make for the mothers to enroll in the community-based health insurance.

As a limitation, it is difficult to remember the accurate contents provided by health extension workers during the postnatal period because of the recall bias. The information relies on mothers' response which was not supported by postnatal checklist. In this study, though, perceived economic status was used, the household wealth status was not assessed as a factor which may affect PNHVs.

\section{Conclusion}

Our findings show that the coverage of postnatal home visits by HEWs remains low in rural districts of Northern Ethiopia. The factors associated with PNHVs include a home visit by HEWs during pregnancy, participation in the pregnant women forum, birth notification and, being a member of community health insurance. Existing health systems should consider interventions that improve pregnancy and birth notification strategies and more efforts should be made in improving communitybased participation and linkages with community health workers.

\section{Abbreviations}

ANC: Antenatal Care; AOR: Adjusted Odds Ratio; BSc: Bachelor of Science; CHWs: Community Health Workers; Cl: Confidence Interval; CV: Coefficient of Variance; EDD: Expected Date of Delivery; EDHS: Ethiopia Demographic Health Survey; EMDHS: Ethiopia Mini Demographic Health Survey; HEWs: Health Extension Workers; IRB: Institutional Review Board; L10K: Last Ten Kilometer; OR: Odds Ratio; PNC: Postnatal Care; PNHVs: Postnatal Home Visits; Roh: Rate of Homogeneity; SD: Standard Deviation; SPSS: Statistical Packages for Social Science; UNICEF: The United Nations International Children's Emergency Fund; WDG: Women Development Groups; WHO: World Health Organization

\section{Acknowledgments}

The authors are grateful to the Tigray regional health bureau and the four district health offices for their facilitation and support of the fieldwork. Lastly, the authors would like to thank the data collectors and the study participants.

\section{Authors' contributions}

All authors have read and approved the final version of the manuscript. Research concept developed by YBT ABK TGG HGD AAM. Research questionnaire development by YBT ABK TGG HGD AAM. Data collection and analysis: YBT ABK TGG. Wrote the paper: YBT ABK TGG HGD AAM

\section{Funding}

This study was financially supported by Adigrat University and the "Tigray KMC Project" which is funded by Bill and Melinda Gates foundation and World Health Organization; Grant Number: 201526690. The funding body had no any role in the design of the study, collection, analysis, interpretation of data, and in writing the manuscript.

\section{Availability of data and materials}

The datasets used and/or analyzed during the current study will be available from the corresponding author on reasonable request.

\section{Ethics approval and consent to participate}

This study was approved by the Institutional Review Board of Mekelle University (IRB No.1437/2018). Verbal consent was obtained from the participants. The use of verbal consent was approved by the ethics committee.

\section{Consent for publication}

Not applicable.

\section{Competing interests}

We, the authors, declare that we don't have any competing interests.

\section{Author details}

${ }^{1}$ College of Medicine and Health Sciences, Adigrat University, Adigrat, Ethiopia. ${ }^{2}$ Mekelle University, College of Health Sciences, School of Public Health, Mekelle, Ethiopia. ${ }^{3}$ Tigray Regional Health Bureau, Mekelle, Ethiopia.

Received: 22 September 2019 Accepted: 8 May 2020

Published online: 19 May 2020

References

1. Sines E, Syed U, Wall S, Worley H. Postnatal care: a critical opportunity to save mothers and newborns. Policy Perspectives on Newborn Health 2007:1-7

2. Central SA. Ethiopia mini demographic and health survey 2019. Indicators. In: Program TD, ICF Rockville M, USA, editors.: Central Statistical Agency Addis Ababa, Ethiopia; 2019.

3. Kerie MW, Deressa AA. Contribution of the health services extension program to improve coverage and comprehensiveness of primary health care services in Jimma zone, Southwest Ethiopia. 
4. Workineh YG, Hailu DA. Factors affecting utilization of postnatal care service in Jabitena district, Amhara region, Ethiopia. Sci J Public Health. 2014;23: 169-76

5. Limenih MA, Endale ZM, Dachew BA. Postnatal care service utilization and associated factors among women who gave birth in the last 12 months prior to the study in Debre Markos town, Northwestern Ethiopia: a community-based cross-sectional study. Int J Reprod Med; 2016.

6. Akibu M, Tsegaye W, Megersa T, Nurgi S. Prevalence and Determinants of Complete Postnatal Care Service Utilization in Northern Shoa, Ethiopia. J Pregnancy; 2018

7. Ugboaja JO, Berthrand NO, Igwegbe AO, OBI-Nwosu AL. Barriers to postnatal care and exclusive breastfeeding among urbanwomen in southeastern Nigeria. Nigerian medical journal: journal of the Nigeria Medical Association;54(1):45.

8. DiBari JN, Yu SM, Chao SM, Lu MC. Use of postpartum care: predictors and barriers. J Pregnancy. 2014

9. Probandari A, Arcita A, Kothijah K, Pamungkasari EP. Barriers to utilization of postnatal care at village level in Klaten district, central Java Province, Indonesia. BMC Health Serv Res. 2017;17(1):541.

10. Tarekegn SM, Lieberman LS, Giedraitis V. Determinants of maternal health service utilization in Ethiopia: analysis of the 2011 Ethiopian Demographic and Health Survey. BMC Pregnancy Childbirth. 2014;14(1):161.

11. Czuk CL. Women's perceptions of postpartum appointment keeping barriers; 1997

12. Sinha LN, Kaur P, Gupta R, Dalpath S, Goyal V, Murhekar M. Newborn care practices and home-based postnatal newborn care programmeâ€"Mewat, Haryana, India, 2013. Western Pacific surveillance and response journal: WPSAR;5(3):22

13. Varma DS, Khan M, Hazra A. Increasing postnatal care of mothers and newborns including follow-up cord care and thermal care in rural Uttar Pradesh. J Fam Welf. 2010;56:31-42.

14. Gogia S, Sachdev HS. Home visits by community health workers to prevent neonatal deaths in developing countries: a systematic review. Bull World Health Org. 2010;88:658-66.

15. Victora CG, Requejo JH, Barros AJ, Berman P, Bhutta Z, Boerma T, Chopra M, De Francisco A, Daelmans B, Hazel E, Lawn J. Countdown to 2015: a decade of tracking progress for maternal, newborn, and child survival. Lancet. 2016; 387(10032):2049-59.

16. Hodgins S, McPherson R, Kerber K. Postnatal care with a focus on home visitation: A design decision-aid for policymakers and program managers. Global Health. 2018;8(1).

17. Bilal NK, Herbst $\mathrm{CH}$, Zhao F, Soucat A, Lemiere C. Health extension workers in Ethiopia: improved access and coverage for the rural poor. Yes Africa Can: Success Stiroes from a Dynamic Continent. 2011:433-43.

18. Warren C, Daly P, Toure L, Mongi P. Postnatal care. Opportunities for Africaâ $€ \ddot{Y}$ s newborns Cape Town, South Africa: Partnership for Maternal, newborn and child Health. 2006:79-90.

19. McPherson R, Hodgins S. Postnatal home visitation: lessons from country programs operating at scale. J Glob Health 2018:8(1).

20. Sitrin D, Guenther T, Murray J, Pilgrim N, Rubayet S, Ligowe R, et al. Reaching mothers and babies with early postnatal home visits: the implementation realities of achieving high coverage in large-scale programs. PLoS One. 2013:8(7):e68930.

21. Gebretsadik A, Alemayehu A, Teshome M, Mekonnen M, Haji Y. Homebased neonatal care by Health Extension Worker in rural Sidama Zone southern Ethiopia: a cross-sectional study. Pediatric health, medicine and therapeutics. 2018;9:147.

22. EDHS ED. Health Survey. Key indicators report 2016.

23. SEZAO. (South-eastern Zone Administrative Office) of Tigray region: Annual reports. 2018, Mekelle, Ethiopia.

24. Koblinsky M, Tain F, Gaym A, Karim A, Carnell M, Tesfaye S. Responding to the maternal health care challenge: The Ethiopian Health Extension Program. Ethiop J Health Dev. 2010;24(1).

25. Hanson C, Manzi F, Mkumbo E, Shirima K, Penfold S, Hill Z, et al. Effectiveness of a home-based counselling strategy on neonatal care and survival: a cluster-randomised trial in six districts of rural southern Tanzania. PLoS Med. 2015;12(9).

26. WHO/UNICEF. Informal meeting on provision of home-based care to mother and child in the first week after birth: follow-up to the Joint WHO. 2012.

27. Callaghan-Koru JA, Nonyane BA, Guenther T, Sitrin D, Ligowe R, Chimbalanga E, Zimba E, Kachale F, Shah R, Baqui AH. Contribution of community-based newborn health promotion to reducing inequities in healthy newborn care practices and knowledge: evidence of improvement from a three-district pilot program in Malawi. BMC Public Health. 2013;13(1): 1052

28. Callaghan-Koru JA, Seifu A, Tholandi M, de Graft-Johnson J, Daniel E, Rawlins B, Worku B, Baqui AH. Newborn care practices at home and in health facilities in 4 regions of Ethiopia. BMC Pediatr. 2013;13(1):198.

29. Namazzi G, Okuga M, Tetui M, Muhumuza Kananura R, Kakaire A, Namutamba S, Mutebi A, Namusoke Kiwanuka S, Ekirapa-Kiracho E, Waiswa $P$. Working with community health workers to improve maternal and newborn health outcomes: implementation and scale-up lessons from eastern Uganda. Global Health Action. 2017;10(sup4):1345495

30. Kirkwood BR, Manu A, ten Asbroek AH, Soremekun S, Weobong B, Gyan T, Danso S, Amenga-Etego S, Tawiah-Agyemang C, Owusu-Agyei S, Hill Z. Effect of the Newhints home-visits intervention on neonatal mortality rate and care practices in Ghana: a cluster randomised controlled trial. Lancet. 2013;381(9884):2184-92.

31. Legesse H, Degefie T, Hiluf M, Sime K, Tesfaye C, Abebe H, Kebede H, Pearson L, Kassaye A, Taylor M. National scale-up of integrated community case management in rural Ethiopia: implementation and early lessons learned. Ethiop Med J. 2014;52(Suppl 3):15-26.

32. Mangham-Jefferies L, Mathewos B, Russell J, Bekele A. How do health extension workers in Ethiopia allocate their time?. Hum Resour Health. 2014 12(1):61.

33. Sitrin D, Guenther T, Waiswa P, Namutamba S, Namazzi G, Sharma S, Ashish KC, Rubayet S, Bhadra S, Ligowe R, Chimbalanga E. Improving newborn care practices through home visits: lessons from Malawi, Nepal, Bangladesh, and Uganda. Global Health Action. 2015;8(1):23963.

34. Tesfaye S, Barry D, Gobezayehu AG, Frew AH, Stover KE, Tessema H, Alamineh L, Sibley LM. Improving coverage of postnatal care in rural Ethiopia using a community based, collaborative quality improvement approach. J Midwifery Womens Health. 2014;59(s1):S55-64.

35. Edmond KM, Yousufi K, Anwari Z, Sadat SM, Staniczai SM, Higgins-Steele A, Bellows AL, Smith ER. Can community health worker home visiting improve care-seeking and maternal and newborn care practices in fragile states such as Afghanistan? A population-based intervention study. BMC Med. 2018; 16(1):106.

36. Sakeah E, Aborigo R, Sakeah JK, Dalaba M, Kanyomse E, Azongo D, Anaseba D, Oladokun S, Oduro AR. The role of community-based health services in influencing postnatal care visits in the Builsa and the West Mamprusi districts in rural Ghana. BMC Pregnancy Childbirth. 2018;18(1):295.

\section{Publisher's Note}

Springer Nature remains neutral with regard to jurisdictional claims in published maps and institutional affiliations.

Ready to submit your research? Choose BMC and benefit from:

- fast, convenient online submission

- thorough peer review by experienced researchers in your field

- rapid publication on acceptance

- support for research data, including large and complex data types

- gold Open Access which fosters wider collaboration and increased citations

- maximum visibility for your research: over $100 \mathrm{M}$ website views per year

At BMC, research is always in progress.

Learn more biomedcentral.com/submissions 